\title{
Molecular Characterization and Phylogenetic Analysis of Culex quinquefasciatus by DNA Barcoding
}

\author{
Samba Shiva Daravath ${ }^{1}$, M. Siddaiah ${ }^{2}$, B. ReddyaNaik ${ }^{2}$ \\ ${ }^{1}$ Department of Biotechnology, Nizam College (OU), Hyderabad, India \\ ${ }^{2}$ Department of Zoology, University College of Science, Osmania University, Hyderabad, India \\ Email: shivabt07@gmail.com, siddaiahmadpathi@gmail.com, srripou@gmail.com
}

Received 30 April 2015; accepted 20 July 2015; published 23 July 2015

Copyright (C) 2015 by authors and Scientific Research Publishing Inc.

This work is licensed under the Creative Commons Attribution International License (CC BY). http://creativecommons.org/licenses/by/4.0/

(c) (7) Open Access

\begin{abstract}
The southern house mosquito, Culex quinquefasciatus, predominantly exists all through the tropics acts as a vector causing several parasitic diseases; it is very important mosquito in transmitting certain diseases which include filariasis. The progression of this disease is due to swift urbanization. In fact, morphological identification mosquito species is very difficult task; moreover, origin of the species is unpredictable. Recently, DNA barcoding of partial mitochondrial COI gene is very popular in DNA based identification of mosquito species. Timely reporting of mosquitoes is very crucial in vector born disease control. In this respect, in the present study, larvae of Culex quinquefasciatus species in Hyderabad, India was collected and reared to adults. Total DNA including mitochondrial DNA was isolated and partial mitochondrial COI gene was amplified. Interestingly, Hyderabad species sequence is found to be novel when compared to other geographical regions of the world, therefore, the same sequence was submitted to NCBI-Nucleotide database and accession number of JX08870 was assigned; to confirm it further, multiple alignment of Culex species was accomplished. Further, phylogenetic analysis was carried out to check the evolutionary pattern of Hyderabad species. In conclusion, partial mitochondrial COI gene of Hyderabad species is found to be novel and it can be used as DNA barcode for molecular characterization. Sequence alignment and phylogenetic analysis revealed that Hyderabad species is more close to UK species.
\end{abstract}

\section{Keywords}

Culex quinquefasciatus, DNA Barcode, Filariasis, COI Gene, Phylogeny

\footnotetext{
${ }^{*}$ Corresponding author.
}

How to cite this paper: Daravath, S.S., Siddaiah, M. and ReddyaNaik, B. (2015) Molecular Characterization and Phylogenetic Analysis of Culex quinquefasciatus by DNA Barcoding. Advances in Entomology, 3, 118-124. 


\section{Introduction}

Culex quinquefasciatus, a mosquito that belongs to the phylum Arthopoda, is an important factor causing filariasis [1], St. Louis encephalitis [2], West Nile virus [3] and Avion malaria [4]. Culex quinquefasciatus, also called the southern house mosquito, is extensively studied as it transmits crucial diseases [5]. Culex mosquitoes are found majorly in the urban cities due to swift urbanization [6], because of uncanny city growth, which eventually results in the progress of the disease transmission [7]-[9]. Lymphatic filariasis is spread worldwide; affecting 120 million people [10]. They generally bite on the lower limbs [11] and causes skin allergies [12]. Since 1979, there are reports on Japanese encephalitis in India [13]. This is also known as cosmopolitan mosquito, because, it acts as vector for protozoan parasites [14], filarial worms [15], and for arboviruses [16] [17]. Culex quinquefasciatus is the prime vector in India causing filariasis [18]; 91\% of them are caused by Wuchereria bancrofti Cobbold [19]. For the human welfare, it is very important to eradicate this species. The genome of mosquito species is generally different in different geometrical areas. Although, the genome sequence of C. quinquefasciatus [20] triggered a new hope for detection, however, the researchers are still involved in identifying and characterizing of these species at molecular level [21]. First, we reported DNA barcodes of Aedes mosquito species [22]. In fact, molecular detection involves identification of species specific sequence. In prokaryotes, particularly in bacteria 16S rRNA based molecular characterization is in practice [23]. Contrastingly, in Molecular nomenclature of the mosquitoes, in mosquito species, the method of DNA barcoding is widely used [24] [25]. The DNA barcoding concept, among all mitochondrial genome genes, uses a 648-base pare region of a mitochondria gene (cytochrome c oxidase I, or COX1) in a study of DNA barcoding of mosquito species.

In this respect, the objective of the present study was focused on the molecular detection of Culex species by DNA barcoding. In addition, from different geographical regions, sequence comparisons and evolutionary relationship among Culex species were studied.

\section{Materials and Methods}

\subsection{Larvae Collection and Characterization}

The wild type Culex larva of C. quinquefasciatus was collected from different parts of the Hyderabad city, India, during the breeding season: stagnant water, coconut shells, tires etc. and reared in the Laboratory under specific conditions according (the room temperature maintained $27^{\circ} \mathrm{C}$ to $29^{\circ} \mathrm{C}$ and $65 \%$ room humidity) manual for Mosquito rearing and experimental techniques published by American Mosquito Control Association (AMCA bulletin no. 5, January 1979) nude mice were used for blood meal to mosquitoes to obtain the pure cultures. This pure culture was reared again to get the F1 generation and the 4th instar larvae of F1 generation were used for genomic DNA extraction [26]. The C. quinquefasciatus was identified morphologically with the help of Entomologist deposited at The National History of Museum, Department of Zoology, Osmania University with Accession No (OUNHM.ART.2013.3). Collected larvae were reared and identified morphologically for Culex quinquefasciatus under the microscope. Microscopic analysis revealed the following characteristics, short and stout head, yellow long mouth brushes. It was also observed that the abdomen has eight segments, the saddle and the siphon, which is four times longer that its width, securing the larvae to be Culex quinquefasciatus. The larvae were allowed to grow into an adult. After morphological characterization, further study was performed from the F1 generation of the pure culture.

\subsection{DNA Extraction}

Genomic DNA was extracted following the procedure of Co.en, and Glover, G. (1982) [27]. From the 4th instar larvae, the total DNA was extracted and was then finely grounded in $50 \mu \mathrm{l}$ of homogenate buffer. The homogenate was left in the thermo cycler for 30 minutes at $60^{\circ} \mathrm{C}$ with a quick addition of $7 \mu \mathrm{l}$ of $8 \mathrm{M}$ Potassium acetate $\left(\mathrm{CH}_{3} \mathrm{COOK}\right)$. Then, incubated the tubes in ice for 30 minutes and centrifuged at maximum speed for 15 minutes; transferred the supernatant into fresh tubes. To precipitate the DNA, incubated the tubes for 15 minutes and after adding $100 \mu \mathrm{l}$ of $95 \%$ ethanol. DNA pellet was collected after rapid centrifugation for 15 minutes at maximum speed. Pellet was air dried and solubilized in tris buffer. DNA was stored at $-20^{\circ} \mathrm{C}$ till further experimental procedure had been carried. 


\subsection{COI Partial Sequence Amplification and Sequencing}

The isolated DNA was further amplified by Polymerase Chain Reaction (PCR) by mitochondrial Cytochrome c Oxidase I (COI) gene, which can differentiate between the diversity of taxa. The mitochondrial COI gene of 501 bp was amplified by primers, the forward primer (5'- ATT GGA TTA TTA GGA TTT ATT G -3') which was designed to start approximately 76 bp into the CO1 5' region and the reverse primer (5'- GCA GGA GGA AGA GTA TGA TAT C -3'), that are available in literature [22]. The reaction mixture of $25 \mu$ l consisting of 10 - 50 ng of DNA template, $200 \mu \mathrm{M}$ of dNTPs, $1 \mu$ of Taq DNA polymerase, $1 \mathrm{x}$ assay buffer and 5 pmol concentration of each primer. PCR conditions: initial denaturation at $94^{\circ} \mathrm{C}$ for 2 min, cycle denaturation at $95^{\circ} \mathrm{C}$ for $30 \mathrm{sec}$, primer annealing at $55^{\circ} \mathrm{C}$ for $30 \mathrm{sec}$, extension at $70^{\circ} \mathrm{C}$ for $30 \mathrm{sec}$, and final extension at $70^{\circ} \mathrm{C}$ for $10 \mathrm{~min}$. The amplicon was confirmed in Agarose gel electrophoresis. The product was given for commercial sequencing (Bio serve Biotechnologies Pvt. Ltd.).

\subsection{Multiple Sequence Alignment}

Multiple sequence alignment (MSA) was performed in Clustal W [28] [29] for partial COI gene sequence of 501 bp with the default parameters. Sequence alignment studies elucidated the similarity and differences among different species in India along with other parts of the world.

\subsection{Phylogenetic Analysis}

The pattern of the evolution of Culex species was studied by phylogenetic analysis. The results of the DNA barcoding were made increasingly vivid with the phylogenetic analysis by the construction of a phylogenetic tree. For phylogeny, the available nucleotide sequences from National Center for Biotechnology Information (NCBI) were collected: Maharashtra, Pondicherry, Japan and UK. In MEGA tool [30] [31], the analysis of the phylogeny was attained by maximum likelihood method with the deletion of gaps and missing data. Furthermore, Bootstrap replication (500 numbers) was used to validate the tree.

\section{Results and Discussions}

The Southern House Mosquito C. quinquefasciatus is a well-known vector, which played a prime role in filariasis and the incidences have seen in different parts of the world. Hence, there is an utmost need to address this problem with priority. In order to snub the prognosis of this vector, it is very essential to take certain control measures. To attain this, the mosquito larvae were collected and grown into an adult. The DNA was isolated and amplified and run on the agarose gel electrophoresis. The agarose wells comprised of sample from different geographical locations along with 200 bp marker DNA is show in Figure 1. The 501 bp amplicons were seen between $400 \mathrm{bp}$ and $600 \mathrm{bp}$ of the DNA marker and were then subjected to sequencing. The sequence is shown in Figure 2; it was noted that the sequence was identified to be novel and was submitted to NCBI-gene bank nucleotide database and the accession number assigned was JX088701.

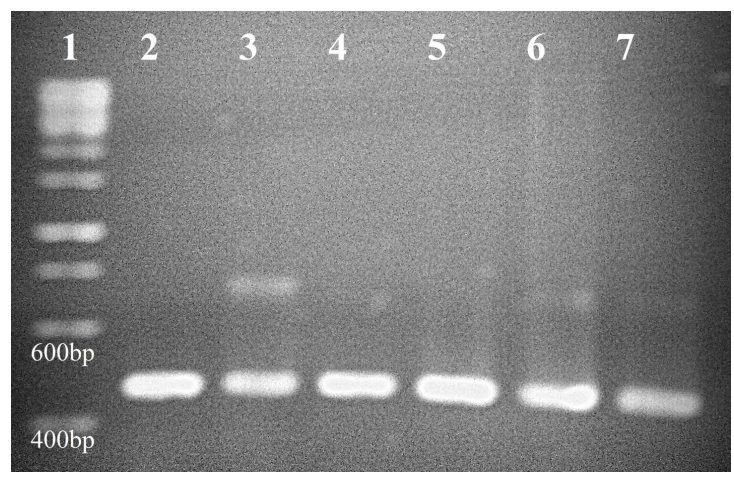

Figure 1. Gel electrophoresis of mitochondrial COI gene isolated from Hyderabad Culex quinquefasciatus mosquito. Lane 1: 200 bp DNA ladder; lane 2-7: PCR products of CO I gene (the samples isolated from different parts of the Hyderabad region). The amplified product of 501bp was corresponded between 400 bp and $600 \mathrm{bp}$. 
Further, Partial mitochondrial COI genes were subjected to multiple sequence alignment on clustal W to speculate the sequence conservations among Culex. species from different geographical locations. From the MSA results, similarities, variations, insertions and deletions were observed. However, Hyderabad Culex species sequence seems more close to UK species as shown in Figure 3 and other species exhibited certain extent of sequence conservation.

Evolutionary pattern of partial mitochondrial COI gene sequence of Hyderabad was checked with Maharashtra, Pondicherry, Japan and UK that were collected from NCBI-Nucleotide database. Phylogenetic analysis reveals that Hyderabad species is more evolutionarily more close to UK species; both the sequences were branched as out group in the tree as shown in Figure 4. All Indian species clustered except one Maharashtra species; this is because of high sequence diversity. In addition to that all Japan species clustered in one group; indicates that they are different from the rest of the species, however, close to Indian species.

Similarly the Evolutionary pattern of partial mitochondrial COI gene sequence of Hyderabad was checked within Indian Culex genus by MSA by bootstrap method in MEGA6 in Figure 5. The critical observation was

\begin{abstract}
>gi|393716453|gb|Jx088701.1| Culex quinquefasciatus cytochrome oxidase subunit 1 (COX1) gene, partial cds; mitochondrial ATTAAAATTTTCAGTTGATTAGCTACTCTTCATGGAACACAATTAAACTATACACCTGCTTTATTATGAT CATTAGGATTTGTATTTTTATTTACTGTTGGAGGATTAACAGGAGTTGTATTAGCTAATTCTTCTATTGA TATTGTTCTTCATGATACATATTATGTTGTTGCTCATTTCCATTATGTATTATCTATAGGAGCTGTATTT GCTATTATAGCAGGATTTATTCACTGATATCCTTTATTAACAGGATTAGTAATAAACCCTACATGATTAA AGATTCAATTTACTATTATATTTATTGGAGTAAATTTAACATTTTTCCCACAACATTTCTTAGGATTAGC AGGAATACCACGACGATATTCTGATTTTCCAGATAGTTACTTAGCATGAAATATTGTTTCATCATTAGGT AGAACAATTTCATTATTTGGAATTGTATTCTTTTTATTTATTATTTGAGAAAGTATAATTTCTCAACGAA САССТTСАTТC
\end{abstract}

Figure 2. Partial mitochondrial sequence of COI gene in NCBI-Nucleotide database with accession number JX088701 shown in FASTA format.

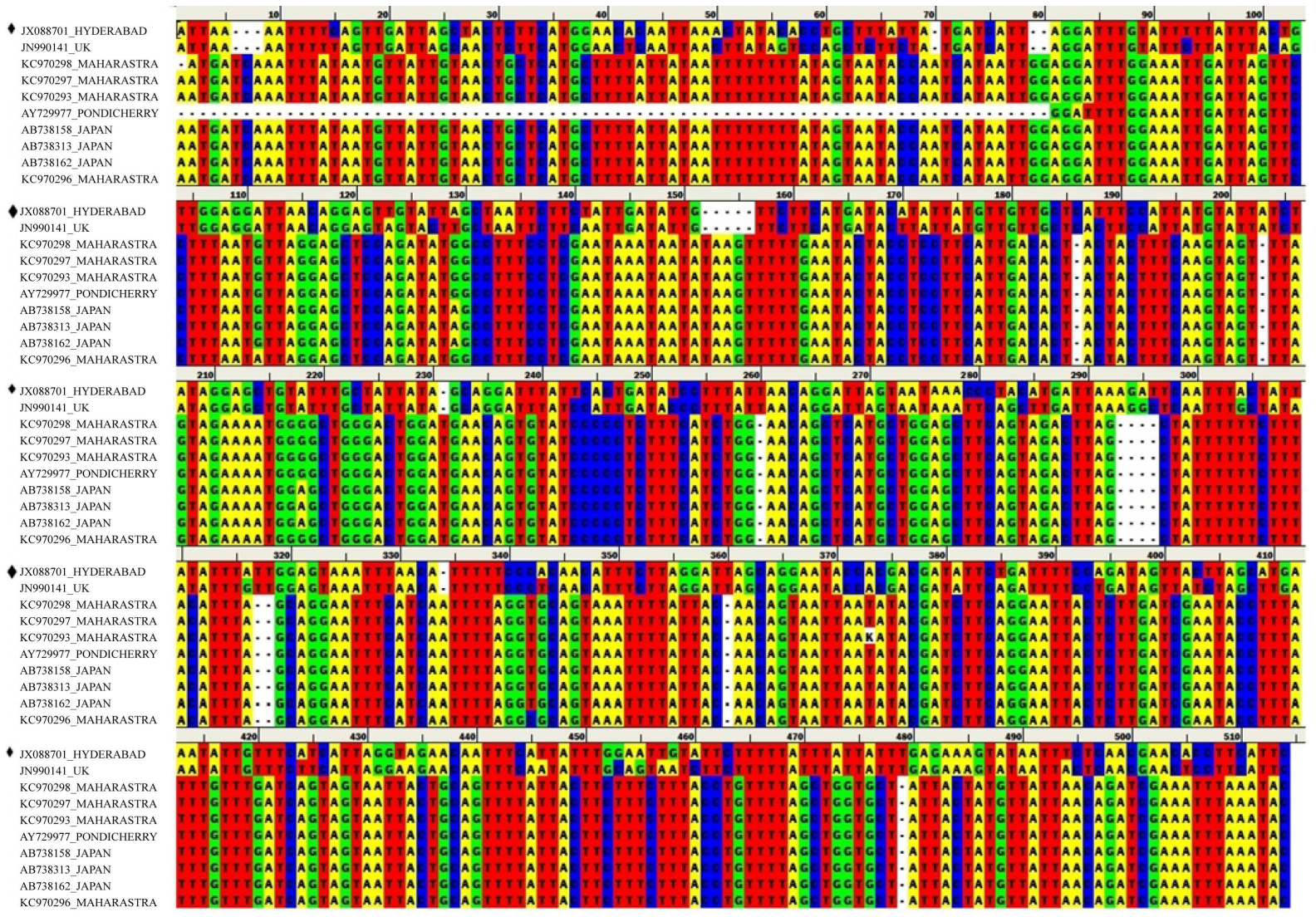

Figure 3. Multiple sequence alignment of partial mitochondrial COI sequences of Culex quinquefasciatus from Hyderabad, Maharashtra, Japan and UK. Sequence alignment was carried out in Clustal W. The sequence of Hyderabad species is more similar to UK species. 


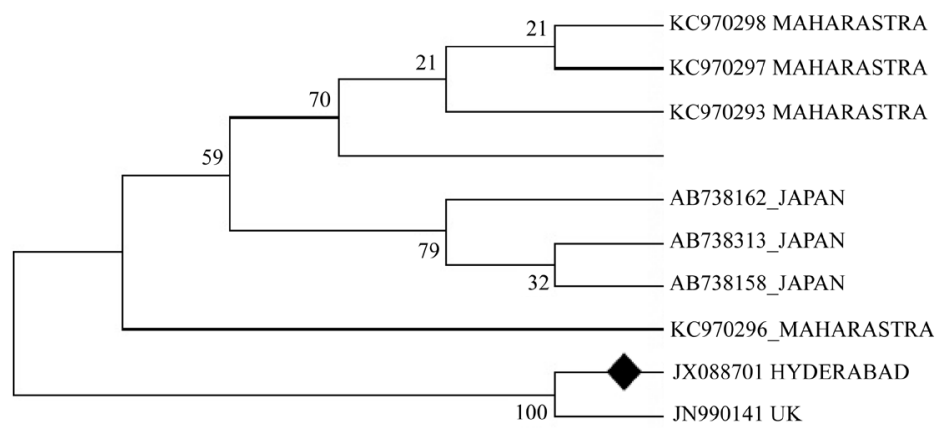

Figure 4. Phylogenetic analysis of partial mitochondrial COI sequences of Culex quinquefasciatus from Hyderabad, Maharashtra, Japan and UK. Noticeably, Hyderabad Culex species is closely related to UK specie. And both emerged as out group in the phylogenetic tree. For phylogenetic analysis Maximum likelihood method with Tamura 3 Parameter model and uniform rates among sites were used. Boot strap method with 500 boot strap replications was used to validate the tree.

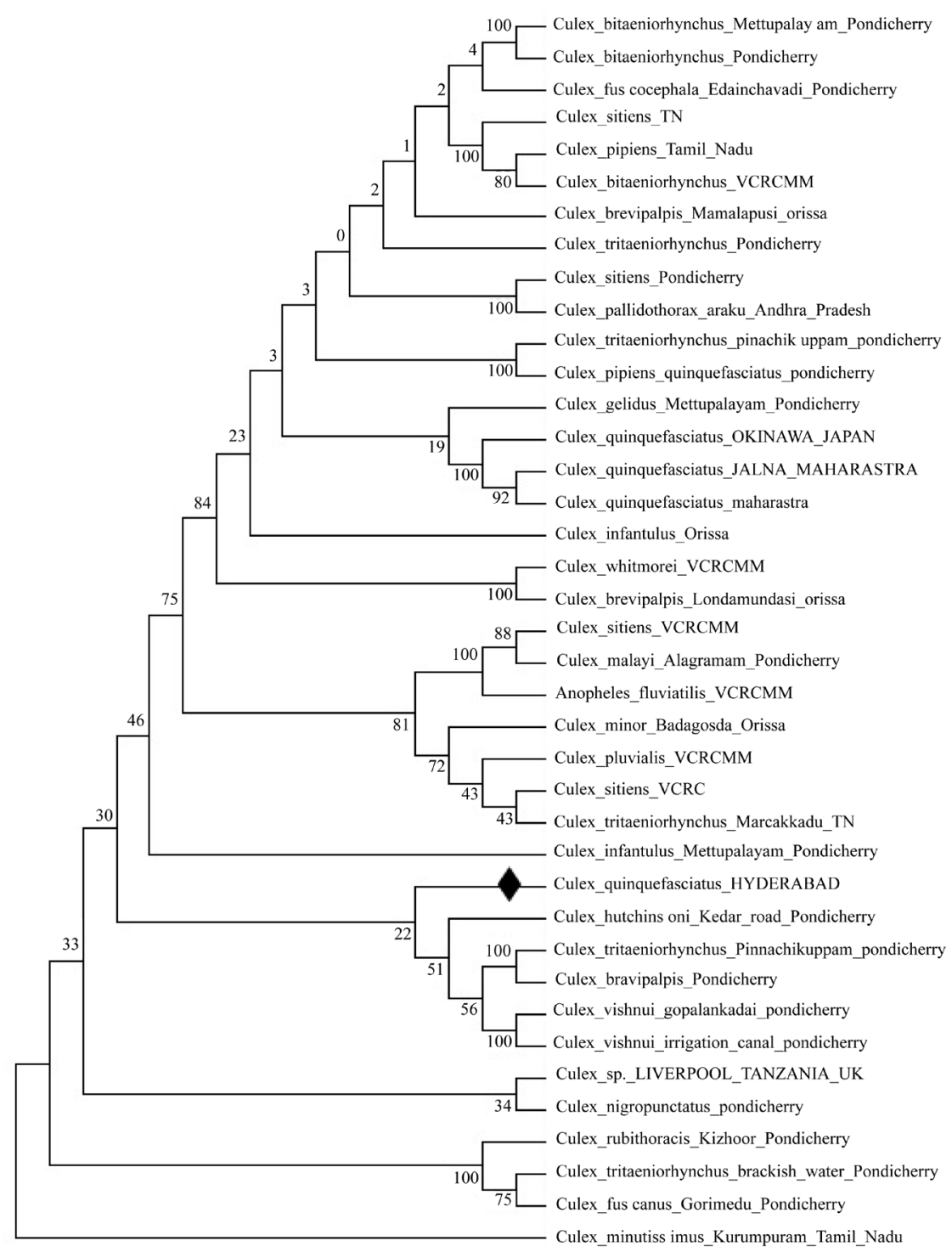

Figure 5. Phylogenetic analysis of partial mitochondrial COI sequences of Culex quinquefasciatus, from Hyderabad within Indian Culex genera. For phylogenetic analysis Maximum likelihood method with Tamura 3 Parameter model and uniform rates among sites were used. Boot strap method with 500 boot strap replications was used to validate the tree. 
found that the Hyderabad species have uniqueness in CO I gene which is evolutionary close to Culexvishnui.

\section{Conclusion}

The medium sized brown mosquito, Culex quinquefasciatus, predominantly exists all through the tropics acts as a vector causing several parasitic diseases. Usually active at night, it is an opportunistic blood feeder which allows the parasites to use the humans as hosts. It is hence important to address their control with priority. In the present study, partial mitochondrial COI DNA sequence was successfully isolated, sequenced and was submitted to NCBI-Nucleotide database. To check the sequence similarity with other species from different geographical regions, multiple sequence alignment of Culex species was accomplished. Sequence alignment suggesting that, Hyderabad species exhibited decent alignment with UK species. To confirm that further phylogeny was constructed. It was noticed that the DNA sequence of Hyderabad Culex species was different from other species and can be used as DNA barcode to identify the organism.

\section{Acknowledgements}

The authors thank the DST-PURSE-OU, DBT-ISLARE and Department Of Zoology for providing infrastructure, RGNF-UGC, New Delhi for financial assistance.

\section{References}

[1] Kumar, D., Chawla, R., Dhamodaram, P. and Balakrishnan, N. (2014) Larvicidal Activity of Cassia occidentals (Linn.) against the Larvae of Bancroftian Fila Coenriasis Vector Mosquito Culex quinquefasciatus. Journal of Parasitology Research, 2014, Article ID: 236838.

[2] Farajollahi, A., Fonseca, D.M., Kramer, L.D. and Marm Kilpatrick, A. (2011) "Bird Biting” Mosquitoes and Human Disease: A Review of the Role of Culex pipiens Complex Mosquitoes in Epidemiology. Infection, Genetics and Evolution: Journal of Molecular Epidemiology and Evolutionary Genetics in Infectious Diseases, 11, 1577-1585. http://dx.doi.org/10.1016/j.meegid.2011.08.013

[3] Styer, L.M., Lim, P.Y., Louie, K.L., Albright, R.G., Kramer, L.D. and Bernard, K.A. (2011) Mosquito Saliva Causes Enhancement of West Nile Virus Infection in Mice. Journal of Virology, 85, 1517-1527. http://dx.doi.org/10.1128/JVI.01112-10

[4] Lalubin, F., Deledevant, A., Glaizot, O. and Christe, P. (2013) Temporal Changes in Mosquito Abundance (Culex pipiens), Avian Malaria Prevalence and Lineage Composition. Parasites \& Vectors, 6, 307. http://dx.doi.org/10.1186/1756-3305-6-307

[5] Dumas, E., Atyame, C.M., Milesi, P., Fonseca, D.M., Shaikevich, E.V., Unal, S., et al. (2013) Population Structure of Wolbachia and Cytoplasmic Introgression in a Complex of Mosquito Species. BMC Evolutionary Biology, 13, 181. http://dx.doi.org/10.1186/1471-2148-13-181

[6] Mattingly, P.F. (1962) Population Increases in Culex quinquefasciatus Wiedemann. A Review of Present Knowledge. Bulletin of the World Health Organization, 27, 579-584.

[7] Singh, D. (1967) The Culex quinquefasciatus Problem in South-East Asia with Special Reference to Urbanization. Bulletin of the World Health Organization, 37, 239-243.

[8] Knudsen, A.B. and Slooff, R. (1992) Vector-Borne Disease Problems in Rapid Urbanization: New Approaches to Vector Control. Bulletin of the World Health Organization, 70, 1-6.

[9] Bivins, R. (2007) “The English Disease” or “Asian Rickets”? Medical Responses to Postcolonial Immigration. Bulletin of the History of Medicine, 81, 533-568. http://dx.doi.org/10.1353/bhm.2007.0062

[10] Ottesen, E.A., Duke, B.O., Karam, M. and Behbehani, K. (1997) Strategies and Tools for the Control/Elimination of Lymphatic Filariasis. Bulletin of the World Health Organization, 75, 491-503.

[11] Oduola, A.O. and Awe, O.O. (2006) Behavioural Biting Preference of Culex quinquefasciatus in Human Host in Lagos Metropolis Nigeria. Journal of Vector Borne Diseases, 43, 16-20.

[12] Singh, B., Singh, P.R. and Mohanty, M.K. (2012) Toxicity of a Plant Based Mosquito Repellent/Killer. Interdisciplinary Toxicology, 5, 184-191. http://dx.doi.org/10.2478/v10102-012-0031-4

[13] Paul, R.C., Rahman, M., Gurley, E.S., Hossain, M.J., Diorditsa, S., Hasan, A.M., et al. (2011) A Novel Low-Cost Approach to Estimate the Incidence of Japanese Encephalitis in the Catchment Area of Three Hospitals in Bangladesh. The American Journal of Tropical Medicine and Hygiene, 85, 379-385. http://dx.doi.org/10.4269/ajtmh.2011.10-0706

[14] Van Riper III, C., Van Riper, S., Goff, M. and Laird, M. (1986) The Epizootiology and Ecological Significance of Ma- 
laria in Hawaiian Land Birds. Ecology Monograph, 56, 327-344. http://dx.doi.org/10.2307/1942550

[15] Ahid, S.M.M., Silva Vasconcelos, P.S.D. and Lourenc, O. (2000) Vector Competence of Culex quinquefasciatus Say from Different Regions of Brazil to Dirofilaria immitis. Memorias do Instituto Oswaldo Cruz, 95, 769-775. http://dx.doi.org/10.1590/S0074-02762000000600004

[16] Sucharit, S., Surathin, K. and Shrestha, S.R. (1989) Vectors of Japanese Encephalitis Virus (JEV): Species Complexes of the Vectors. The Southeast Asian Journal of Tropical Medicine and Public Health, 20, 611-621.

[17] Molaei, G., Andreadis, T.G., Armstrong, P.M., Bueno Jr., R., Dennett, J.A., Real, S.V., et al. (2007) Host Feeding Pattern of Culex quinquefasciatus (Diptera: Culicidae) and Its Role in Transmission of West Nile Virus in Harris County, Texas. The American Journal of Tropical Medicine and Hygiene, 77, 73-81.

[18] Sarkar, M., Bhattacharyya, I.K., Borkotoki, A., Goswami, D., Rabha, B., Baruah, I., et al. (2009) Insecticide Resistance and Detoxifying Enzyme Activity in the Principal Bancroftian filariasis Vector, Culex quinquefasciatus, in Northeastern India. Medical and Veterinary Entomology, 23, 122-131. http://dx.doi.org/10.1111/j.1365-2915.2009.00805.x

[19] Snow, L.C., Bockarie, M.J. and Michael, E. (2006) Transmission Dynamics of Lymphatic Filariasis: Vector-Specific Density Dependence in the Development of Wuchereria bancrofti Infective Larvae in Mosquitoes. Medical and Veterinary Entomology, 20, 261-272. http://dx.doi.org/10.1111/j.1365-2915.2006.00629.x

[20] Arensburger, P., Megy, K., Waterhouse, R.M., Abrudan, J., Amedeo, P., Antelo, B., et al. (2010) Sequencing of Culex quinquefasciatus Establishes a Platform for Mosquito Comparative Genomics. Science, 330, 86-88. http://dx.doi.org/10.1111/j.1365-2915.2006.00629.x

[21] Murty, U.S., Jamil, K., Krishna, D. and Reddy, P.J. (1996) Rule-Based System for the Fast Identification of Species of Indian Anopheline Mosquitoes. Computer Applications in the Biosciences: CABIOS, 12, 491-495. http://dx.doi.org/10.1093/bioinformatics/12.6.491

[22] Sambashiva, D., Aravind, S., Yuvo, S., Swarnagowreeswari, G., Madhavi, Y.M., Smita, C.P., et al. (2014) DNA Barcode of COI Genetic Marker of the Indian Aedesalbopictus (Skuse). Medical Science, 5, 21-25.

[23] Aravind, S., Phazna Devi, T.A., Smita, C.P., Rajesh, G., Srikanth, S. and Kalyan, S. (2012) Molecular Evolution of Pathogenic Bacteria Based on rrsA Gene. Journal of Medical and Allied Sciences, 2, 12-18.

[24] Linton, Y.M., Pecor, J.E., Porter, C.H., Mitchell, L.B., Garzon-Moreno, A., Foley, D.H., et al. (2013) Mosquitoes of Eastern Amazonian Ecuador: Biodiversity, Bionomics and Barcodes. Memórias do Instituto Oswaldo Cruz, 108, 100109.

[25] Engdahl, C., Larsson, P., Naslund, J., Bravo, M., Evander, M., Lundstrom, J.O., et al. (2014) Identification of Swedish Mosquitoes Based on Molecular Barcoding of the COI Gene and SNP Analysis. Molecular Ecology Resources, 14, 478-488. http://dx.doi.org/10.1111/1755-0998.12202

[26] Daravath, S., Yadav, M.M., Chakrapani, P. and Naik, B.R. (2013) Molecular Identification of Aedesalbopictus (Diptera: Culicidae) and Quantitative Analysis of COI Gene in South-Indian Species. International Journal of Current Microbiology and Applied Sciences, 2, 102-109

[27] Coen, E.S., Strachan, T. and Glover, G. (1982) Dynamics of Concerted Evolution of Ribosomal DNA and Histone Gene Families in the Melanogaster Species Subgroup of Drosophila. Journal of Molecular Biology, 158, 17-35. http://dx.doi.org/10.1016/0022-2836(82)90448-X

[28] Thompson, J.D., Higgins, D.G. and Gibson, T.J. (1994) CLUSTAL W: Improving the Sensitivity of Progressive Multiple Sequence Alignment through Sequence Weighting, Position-Specific Gap Penalties and Weight Matrix Choice. Nucleic Acids Research, 22, 4673-4680. http://dx.doi.org/10.1093/nar/22.22.4673

[29] Larkin, M.A., Blackshields, G., Brown, N.P., Chenna, R., McGettigan, P.A., McWilliam, H., et al. (2007) Clustal W and Clustal X Version 2.0. Bioinformatics, 23, 2947-2948. http://dx.doi.org/10.1093/nar/22.22.4673

[30] Hall, B.G. (2013) Building Phylogenetic Trees from Molecular Data with MEGA. Molecular Biology and Evolution, 30, 1229-1235. http://dx.doi.org/10.1093/molbev/mst012

[31] Smith, S.A., Beaulieu, J.M. and Donoghue, M.J. (2009) Mega-Phylogeny Approach for Comparative Biology: An Alternative to Supertree and Supermatrix Approaches. BMC Evolutionary Biology, 9, 37.

http://dx.doi.org/10.1186/1471-2148-9-37 